\title{
Introduce 3D Modelling and Virtual Technology to High School Art Education
}

\author{
Chenxuan Meng ${ }^{1 *}$ \\ ${ }^{1}$ University of Toronto, John H. Daniels Faculty of Architecture, Landscape, and Design \\ *Corresponding author. Email: chenxuan.meng@mail.utoronto.ca
}

\begin{abstract}
In the design field, 3D modelling combined with simulation technology which is considered as one of the most important tools has already been introduced in higher education. In response to the growing awareness of the importance of design creativity, many educators are incorporating design courses into their traditional art education programs in high school. In this paper, we mainly investigated the possibility and challenges of applying 3D technology into art education in high school. This topic is urgent and necessary because 3D technology-based art education enables students to learn about spatial relationships, thus stimulating their spatial logic and imagination more effectively than traditional art education in high school.
\end{abstract}

Keywords: High School Art Education, 3D technology, 3D modelling, 3D virtual, Design Education

\section{INTRODUCTION TO THE COMBINATION OF 3D MODELLING AND SIMULATION TECHNOLOGY}

Three-dimensional (3D) technologies are used to create real-life and virtual experiences [1], which can be classified into 3D modelling, 3D virtual, 3D printing, and so on. The idea of 3D modeling was initiated in the 1960s by Ivan Sutherland, the developer of Sketchpad, as a method of producing a three-dimensional representation of an object utilizing specialized software. [2] Then, 3D modelling and virtual technology developed rapidly throughout the 1990s and an increasing number of people thus had the opportunities to get access to it. Currently, the technology has spead to an extensive range of fields. A number of equipment and technology derivatives are available and ready to bring humans closer to experiencing 3D space, such as Virtual Reality (VR) technology.

There are a variety of industries that effectively integrate 3D technology into their scopes, including medicine, television and film production, software development, and animation. One of the most convincing examples is the design industry. Software such as 3D Max, Rhino, SketchUp, and others are used to enable designers to unleash and practice their creativity; other software, including Lumion and Enscape, work in tandem with these modeling tools to produce a more realistic simulation and provide users with a more immersive walk-through experience.

The professionalism and sense of space of 3D modeling simulation softwares render the full-scale simulation space an ideal venue to present design concepts. In this regard, the use of $3 \mathrm{D}$ modelling and simulation technologies has become applicable and pervasive in professional courses at universities and colleges. In addition, since the three-dimensional space created by 3D modelling and simulation encourages the potential designers to exercise their special imaginative ability, this technology is also believed to cultivate students' space imagination in high school art classes. On the one hand, it can exert a positive impact on high schoolers' general creativity. On the other hand, some scholars assumed that technology reflects the aesthetics of modern culture to some extent. [3] Accordingly, 3D technology can provide penetrating insights into new teaching methods in high school art courses.

\section{APPLYING 3D VIRTUAL TECHNOLOGY INTO ART EDUCATION}

\subsection{Traditional teaching technology in current art education}

In high schools today, art education is largely traditional, comprising merely two primary subjects: music and painting. This is mainly because art classes 
have received little attention in the current educational environment featuring with the test-oriented and careerled requirement. In art education, one part of the curriculum is to cultivate students' appreciation for art by analyzing and comprehending the work of famous artists. Besides, there are also some courses where students may master the fundamental knowledge of drawings, such as sketching and watercolour.

The traditional art classroom can function as an incomparably effective platform for students to learn how to use art to express students' emotions and convey their thoughts, which is also one of the characteristics of art education.[4] In this sense, students who are under test-oriented education can release the learning pressure and edify their sentiment. Meanwhile, the current format of art appreciation courses is well-suited and appropriate for the restricted time left for art education in high school. Students are not required to conduct projects or complete assignments in this program, and at the same time, they can enrich their art knowledge and enhance their aesthetic accomplishment.

There are also certain disadvantages to this type of art education. Many of these courses are deemed "useless" since they rarely yield substantial outputs or achievements from the students. However, art classes in high school are vital because it is not designed for accomplishing lucrative purposes such as obtaining a prosperous career. Also, it can stimulate students' creativity and expressive skills, thereby expanding their employment options.

\subsection{Overview of $3 D$ Virtual technology using in art education}

As I mentioned previously, 3D technologies are already widely employed in the design field. It is potential for achieving mutual benefits between the designers and the customers as the former ones can convey their designing perceptions in a threedimensional virtual space, and the latter ones can thus intuitively examine the design plans from any angle. Considering an architectural design, architects present their inspirations through 3D models, which are different from the traditional 2D sketches and physical models. Digital models are more economical and more time-efficient, and at the same time, they enable plans to be adjusted and modified in time.[5] In addition, through some rendering or virtual software, designers can easily choose, change, and apply any material to the design scheme, and can also simulate the way people interact with indoor and outdoor spaces.

\subsubsection{The current situation of using $3 D$ technology in art education}

Typically, these types of software are taught in vocational programs at colleges and universities. The following are some of the reasons behind this:

1. Universities or colleges teach courses on $3 \mathrm{~d}$ modeling softwares since some of them are used in work situations and involves multidisciplinary cooperation.

2. Students will learn by themselves some easy-touse simulation softwares once they enter university, and practice through specific design courses. Such opportunities and time are not available to high school students.

3. Professional modelling software is complex and time-consuming to be acquired completely as it requires extensive and Occupational training.

4. Learning 3D software requires high-quality equipment, especially the top-notch computer configuration.

If $3 \mathrm{D}$ technology is introduced into high school art programs, the educators and the students will confront the aforementioned difficulties. Furthermore, it is also urgent to consider the ways in which students can grasp the skills within a limited amount of time.

\subsection{The differences between the $3 D$ modelling virtual technology and the traditional art education method}

\subsubsection{The advantages of $3 D$ modelling virtual technology}

By integrating 3D technology into art education, many advantages can be gained over traditional learning methods. Firstly, students may primarily use 3D technology to create a three-dimensional space and at that time, art is no longer demonstrated on a plane. Then, the 3D technology also captures students' attention to learn the linear motion and the stereotactic space.[6] Since today's educational system leaves limited room for developing children's creativity due to its focus on skills and drills, 3D space, which encourages students' spatial thinking and innovative spirit, seems to be especially valuable. [6]

Secondly, 3D simulation technology is capable of greatly increasing students' interaction and involvement with art. [7] The most straightforward way to interact with the design work is to create a walk-through video using basic simulation software; the second method is to incorporate the design work into an interactive roleplaying game, in which virtual characters can engage in and communicate with the artwork in virtual space. This 
method can not only encourage the involvement between students and designers but the immersive experience of other audiences has also been enhanced to a new level.[8] The last potential method is that the artwork can be transformed into files compatible with VR devices in 3D models, and then students can connect with the artwork through holographic projection.

Furthermore, with 3D technology, students can create a private and secure virtual environment for themselves, which is an indispensable part of art creation. Students can use the ideal environment established in the three-dimensional space as the "basic site" for design. Therefore, teachers should assist students in creating an optimal atmosphere as a foundation for artistic expression so that they can enjoy creative freedom. In the simulated environment, both the students and the teachers have contributed to the innovative hi-tech creation, which serves to pique students' attention and spark their imagination.

Regarding its benefits to self-motivation, since 3D simulation software is similar to the games students enjoy, they are more likely to be interested in 3D technologies. Also, they have been given sufficient autonomy in creating the artwork innovatively and spontaneously. Accordingly, the students can not only enjoy the creative process more their independent consciousness and abilities can be strengthened greatly. [9]

Finally, it satisfies children's developing needs of being able to organize and coordinate as well as team collaboration. Traditional paintings and artworks are typically completed independently, which may need a lot of time and energy to produce. However, 3D projects, instead, can be more of a result of team effort and cooperative endeavor, thereby building students' effective communication skills and expediting their working process at the same time.

\subsubsection{The limitations for the $3 D$ modelling and virtual technology}

While 3D technology has many advantages, it also has certain challenges and problems that need to be overcome. Addiction is the first thing to deal with. Parents and educators are concerned that 3D simulation software such as the "second life" which is a popular electronic arts video game will result in potential addictive problems. For them, maintaining children's life-study balance or turning that addiction into a bargaining chip is very important. As such, the children should set appropriate boundaries and follow a healthy lifestyle to ensure that they are participating in their learning at the right level.[10]

In addition, learning software takes more time than learning traditional hand-drawing and this drawback is worth noticing especially for those with minimal art experience

Thirdly, although 3D modelling software can greatly improve the visibility and interactivity of a design to a certain extent, it can also limit creative thinking when overused. [9] It is possible to solve this problem by combining the usage of hand-painting and 3D software in a reasonable manner.

\section{MAIN METHOD OF RE-DESIGNING HIGH SCHOOL ART CURRICULUM: INTRODUCING 3D MODELLING AND VIRTUAL TECHNOLOGY}

\subsection{Selecting appropriate devices and software for high school students}

Choosing the right software usually represents the initial step of introducing 3D technology. A variety of modelling software is available on the market and for high school students with limited time, a practical one should be easy for starters and can collaborate with numerous other software. Basically, sketch-up is a relatively ideal entry-level modelling software as both the interface and the fundamental functions are simple to understand. In the meantime, the most important feature of the SketchUp software is that it can be used with the 3D simulation software the Second Life, and virtual rendering software. Also, the software Lumion and Enscape are directly linked and can be combined to generate virtual reality. However, these programs also have their limitations. For example, modelling will be challenging if the artworks are primarily made up of curved surfaces. The equipment issues are equally important to the abovementioned processing issues. Generally speaking, 3D rendering simulation software requires high-standard hardware support of the computer devices, so stronger solutions can be implemented for various environments. At the same time, if the computer can be connected with gadgets such as VR devices, people's engagement in the simulation will be further enhanced.

\subsection{Setting a reasonable curriculum arrangement enabling students to build their own virtual space}

Teachers should define and restrict a reasonable scope of the three-dimensional space according to the limited time of the course, and determine the proportion of 3D modelling and simulation technology used throughout courses. To illustrate, if a large-scale spatial environment, such as the overall planning layout of a city, has been chosen as an example in the teaching materials, then the $3 \mathrm{D}$ design of the artwork should be more conceptual and less detailed. However, if the specified space is relatively small, such as one corner of the room, the artwork can be demonstrated and 
displayed in detail. In this sense, teachers are expected to utilize the specific site construction to teach the basic functions of the software, allowing students to build their own three-dimensional space while learning the software.

\subsection{Guiding students to use virtual spaces to present their projects}

The newly emerging design education using 3D technology is different from the traditional single-sided one. The project requires more certain and more specific design objects and the corresponding design context. Undoubtedly, this added practicality and focus in artistic design can better stimulate students' creative thinking and sense of responsibility. At the same time, the project can be completed and presented in the form of a group, which strengthens students' collaboration skills while reducing the burden arising from the previous individual tasks.

\subsection{Exhibiting students' achievements}

It is very important for the students to display their achievements.[11] At the end of the course, students in the design courses in the high school will be required to share the link of their designs. It is considered not only to increase the enthusiasm of the students but also to teach them to appreciate the works of others to further develop their creativity.

\section{CONCLUSION}

3D technology introduces spatial experience and interactivity that can't be expressed by traditional art into the classroom. Students are also more enthusiastic about their art studies because of this stronger sense of participation. This article discusses the feasibility, advantages and curriculum design of the use of 3D modeling technology and simulation technology in high school art classes, starting with the development of 3D technology. Even with the advancement of 3D modeling and simulation technology in high school art classes, there are still many issues and risks. As 3D and related technologies develop, such as VR and 3D printing, the use of $3 \mathrm{D}$ modelling and simulation technology in high schools will also provide more options for art classes.

\section{REFERENCES}

[1] S. Ikuta, Handbook of research on software for gifted and talented school activities in K-12 classrooms. .

[2] "The History of Computer-Aided Design (CAD) 3D Innovations", 3D Innovations, 2021. [Online]. Available: https://3d-innovations.com/blog/thehistory-of-computer-aided-design-cad/. [Accessed: 28- Sep- 2021].
[3] Hsu and Lai, "Why Should Computational Work and Aesthetics Be Taught in the Art Classroom?", Visual Arts Research, vol. 39, no. 2, p. 1, 2013. Available: 10.5406/visuartsrese.39.2.0001.

[4] ZWIRN, SUSAN GOETZ. "Teachers Who Create, Artists Who Teach." The Journal of Creative Behavior, vol. 39, no. 2, 2005, pp. 111-122., https://doi.org/10.1002/j.21626057.2005.tb01253.x

[5] SMITH, John. The DATA Lecture - The Current and Future Role of Modelling in Design and Technology. Journal of Design \& Technology Education, [S.1.], v. 6, n. 1, july 2009. ISSN 13601431. Available at: <https://ojs.lboro.ac.uk/JDTE/article/view/430

[6] K. Hew and W. Cheung, "Use of three-dimensional (3-D) immersive virtual worlds in K-12 and higher education settings: A review of the research", British Journal of Educational Technology, vol. 41, no. 1, pp. 33-55, 2008. Available: 10.1111/j.14678535.2008.00900.x.

[7] Lu, Li-Fen Lilly. "A Art Café: A 3d Virtual Learning Environment for Art Education." Art Education, vol. 61, no. 6, 2008, pp. 48-54., https://doi.org/10.1080/00043125.2008.11652077.

[8] "The Ed Media Center: A second life professional ... - eric." [Online]. Available: https://files.eric.ed.gov/fulltext/ED578675.pdf. [Accessed: 05-Oct-2021].

[9] Han, Hsiao-Cheng (Sandrine). "Virtual World Construction and the Relationship to Creativity in Art Education / Construction De Mondes VIRTUELS Et Lien Avec LA Créativité En ÉDUCATION ARTISTIQUE." The Canadian Review of Art Education / Revue Canadienne d'Éducation Artistique, vol. 46, no. 1, 2019, pp. 85-100., https://doi.org/10.26443/crae.v46i1.44.

[10] J. Gaimster, "Reflections on Interactions in virtual worlds and their implication for learning art and design", Art, Design \& Communication in Higher Education, vol. 6, no. 3, pp. 187-199, 2008. Available: 10.1386/adch.6.3.187_1.

[11] Han, Hsiao-Cheng. "Gamified Pedagogy: From Gaming Theory to Creating a Self-Motivated Learning Environment in Studio Art." Studies in Art Education, vol. 56, no. 3, 2015, pp. 257-267., https://doi.org/10.1080/00393541.2015.11518967. 